\title{
Effect analysis of residual magnetism availability level on the success of voltage generation processes in self-excited induction generators
}

\author{
Refdinal Nazir, Syafii, Andi Pawawoi, Fajril Akbar, Yudi Arfan \\ Department of Electrical Engineering, Andalas University, Indonesia
}

\begin{abstract}
Article Info
Article history:

Received Nov 16, 2019

Revised Feb 4, 2020

Accepted Apr 26, 2020

\section{Keywords:}

Excitation curve

Magnetization curve

Residual magnetism

SEIG

Voltage generation

ABSTRACT

The voltage generation process is a very crucial initial stage for the successful operation of the self-excited induction generator (SEIG). The availability of residual magnetism and the adequacy of excitation capacitor value are factors that determine the success of the voltage generation process on the SEIG. This paper analyzes the effect of the availability of residual magnetism on the rotor's magnetic core. With a simple approach, the terminal voltage on the SEIG can be solved through the intersection between the magnetization curve $(\mathrm{Xm})$ and the excitation curve (Xce). The shape and equation of the magnetization curve will be affected by the availability of residual magnetism. The change in residual magnetism availability will cause a change in the intersection point between the magnetization curve $(\mathrm{Xm})$ and the excitation curve (Xce), which will determine the value of voltage generated by the generator. In this study, Newton Rhapson's method with numerical iteration approach has been used to analyze the effect of changes in the availability of residual magnetism on the success of voltage generation on the SEIG. The analysis results have been shown that the availability of residual magnetism with residual voltage values below 1.04 Volt will cause the failure of the SEIG to generate the terminal voltage at its nominal value. Meanwhile, the availability of residual magnetism in SEIG with residual voltage values above 1.04 Volt, will succeed in generating terminal voltage at its nominal value. For SEIG used as the object of this study, the value of Eres $=1.04$ Volt is a critical value of the availability of residual magnetism.
\end{abstract}

This is an open access article under the CC BY-SA license.

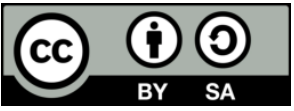

Corresponding Author:

Refdinal Nazir,

Department of Electrical Engineering,

Andalas University, Indonesia

Jalan Dr. Mohammad Hatta Padang 25163, Indonesia.

Email: refdinalnazir@yahoo.co.id

\section{INTRODUCTION}

Currently, the application of induction generators in power plants is increasingly rivaling the use of synchronous generators, especially in small scale power plants that are driven by renewable energy sources, such as micro hydro power plants, wind power, biomass power, etc. [1-4]. This is mainly due to the induction generator (squirrel-cage rotor) has a number of advantages over synchronous generators, including: strong and simple rotor construction, minimal maintenance, simple operation, has the ability to self-protection. In addition, induction generators are more resistant to harmonic currents generated by non-linear loads or electronic load controllers (ELC) [5-8]. There are 2 operating patterns of induction generators applied, namely: operation as a stand-alone generator and operation as a generator connected to the grid $[3,9]$. 
The operation of a stand-alone induction generator, better known as the Self-Excited Induction Generator (SEIG), is generally used in small-scale power plants in off-grid areas. While the operation of induction generators with grid-connected patterns is generally applied to the distributed generation (DG) in on-grid areas. The study in this paper is focused to analyze the operation of SEIG.

Besides the rotation of the prime mover, there are two variables that determine the success of the SEIG operation, namely: the availability of the residual magnetism at the time of initiation and the adequacy of the reactive power during the excitation process. The reactive power needs of the induction generator are used to generate a magnetic field in the air gap, which is needed to produce the induced voltage [10]. In SEIG, the reactive power requirements are supplied from the excitation capacitor, which is connected in parallel with the generator terminal. The availability of residual magnetism in the iron core of the SEIG rotor is absolutely necessary to generate the initial voltage of the generator $\left(E_{\text {res }}\right)$, and then as a trigger for the initial excitation current $\left(I_{\mathrm{e} 0}\right)$ [11]. The unavailability of residual magnetism or the reduction in its value lower than the critical value will cause the failure of the voltage generation process in the SEIG. The value of residual magnetism availability in the SEIG can be change due to short circuit fault, extra reactive load, and its operated at its critical point [12,13].

The effect of the availability of residual magnetism on the success of voltage generation on SEIG is analyzed in this paper. Graphically, the generation of SEIG terminal voltages at nominal values can be determined from the intersection between the magnetization curve $\left(X_{\mathrm{m}}\right)$ and the excitation curve $\left(X_{\mathrm{ce}}\right)$ [14]. The magnetization curve equation will be affected by the availability of the residual magnetism, while the excitation curve equation is determined by the value of the excitation capacitor. The change in the residual magnetism availability will cause a change in the intersection point between the magnetization curve $\left(X_{\mathrm{m}}\right)$ and the excitation curve $\left(X_{\mathrm{ce}}\right)$, which will determine the amount of voltage generated by the generator. In this study, Newton Raphson's method with a numerical approach is applied to analyze the effect of changes in the availability of residual magnets on voltage generation by SEIG.

\section{THE PROCESS OF VOLTAGE GENERATION ON SEIG}

In the induction generator connected to the grid, the voltage generation process can occur immediately when the generator is paralleled to the grid. This happens because the reactive power needs for the excitation process are directly provided by the grid system. Unlike the induction generator connected to the grid, the reactive power supply in the SEIG is obtained from the excitation capacitor. And the excitation process in SEIG begins with the availability of residual magnetism in its rotor. Therefore, the voltage generation process in SEIG can be broken down into two stages, namely: synchronous operation stage and asynchronous operation stage [15-17].

\subsection{Synchronous mode operation}

The excitation process at the synchronous operating mode stage is triggered by the availability of residual magnetism in the SEIG. The availability of residual magnetism can be checked from the voltage generated at the machine terminals it caused. Measurement of the machine terminal voltage caused by the residual magnetism is performed in the condition that the machine has not been connected to the excitation capacitor and its rotor is rotated in synchronous rotation, as shown in figure 1 . The value of the voltage generated by the residual magnetism in the stator is proportional to the residual magnetism density and the number of rotor rotation. Figure $2 \mathrm{~b}$. shows the waveform of the terminal voltage due to residual magnetism for machines used as study objects and rotated at synchronous rotation. The residual magnetism is formed because of the magnetizing process that has been carried out before the machine is operated, as shown in figure 2. For generators, the magnetizing process is usually implemented until it reaches the flux saturation value $\left(\psi_{\mathrm{s}}\right)$. When the magnetization current is reduced to zero, there is still a magnetic flux stored on the magnetic core of machine rotor. The remaining flux in the magnetic core is known as the remanence flux $\left(\psi_{\mathrm{r}}\right)$. The comparison between the magnitude of the remanence flux with the saturation flux is known as the remanence factor $\left(K_{\mathrm{r}}\right)$ [18]. The remanence factor value of an induction generator is determined by the magnetic core material used [19-21]. The magnitude of the magnetization current will affect the amount of residual magnetism, which automatically also affects the magnitude of voltage that its forms. Figure 3 shows the variation between the magnetization current $I_{\mathrm{m}}$ and the voltage generated at the machine terminal due to residual magnetism $E_{\text {res. }}$ As this figure shows, the magnitude of voltage due to the residual magnetism is proportional to the magnitude of current injected into one of the phase windings of machine stator. 


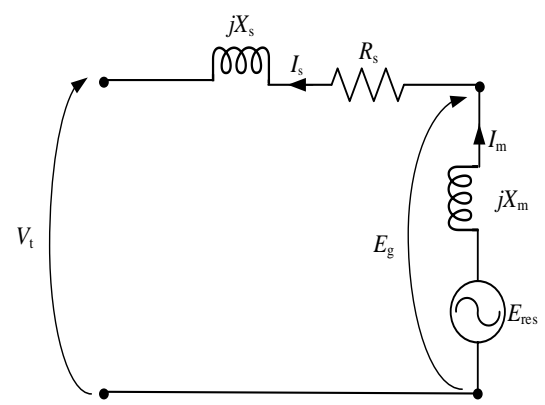

(a)

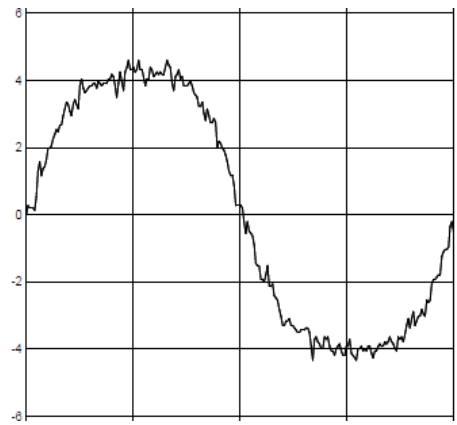

(b)

Figure 1. Voltage due to the induction of residual magnetism (a) equivalent circuit (b) voltage waveform

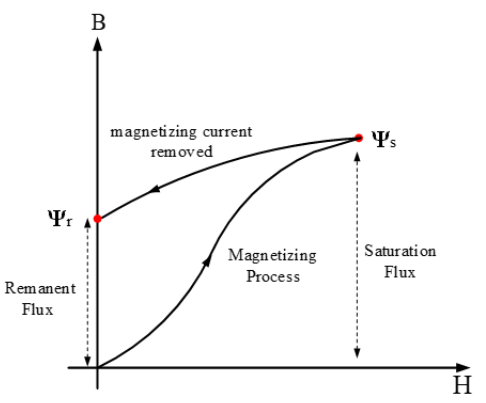

Figure 2. The process of forming residual magnetism

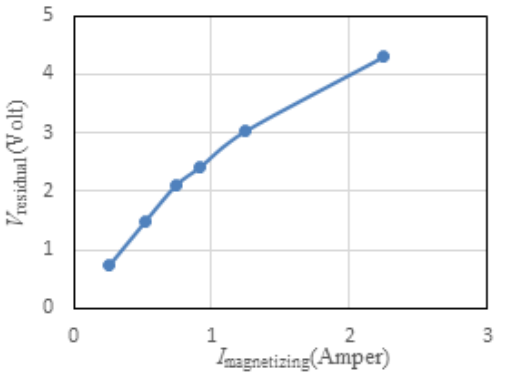

Figure 3. Magnetizing current (Im) versus the voltage due to residual magnetism (Eres)

\subsection{Asynchronous Mode Operation}

The asynchronous operating mode of SEIG in the voltage generation process starts after the excitation capacitor $(\mathrm{Ce})$ is connected on the generator terminal. The SEIG equivalent circuit in the noload condition and the asynchronous operating mode is shown in Figure 4.

In no-load conditions, the rotor current is very small and can be ignored. In this condition, the rotor circuit branch becomes an open circuit, so that the equivalent circuit of SEIG can be simplified as shown in Figure $4 \mathrm{~b}$. In this circuit, $I_{\mathrm{m}}=I_{\mathrm{s}}=I_{\mathrm{e}}$ applies. The air gap voltage curve $\left(E_{\mathrm{g}}\right)$ as a function of $I_{\mathrm{m}}$ is obtained from the saturation test results. The terminal voltage curve $\left(V_{\mathrm{t}}\right)$ as a function of $I_{\mathrm{m}}$ can be solved through the following equation:

$$
V_{\mathrm{t}}=\sqrt{\left(E_{\mathrm{g}}+I_{\mathrm{m}} X_{\mathrm{s}}\right)^{2}+\left(I_{\mathrm{m}} R_{\mathrm{s}}\right)^{2}}
$$

Figure 5 shows the relationship between the magnetization curve $\left(X_{\mathrm{m}}\right)$ and the excitation curve $\left(X_{\mathrm{ce}}\right)$ in the voltage generation process of SEIG. Magnetization curves can be expressed in terms of air gap voltage $\left(E_{\mathrm{g}}\right)$ versus magnetizing current $\left(I_{\mathrm{m}}\right)$ or terminal voltage $\left(V_{\mathrm{t}}\right)$ versus magnetizing current $\left(I_{\mathrm{m}}\right)$, as shown in Figure 5a. For the same machine, the initial value of the magnetization curve will change according to the value of the voltage generated due to residual magnetism. The excitation curve is a linear curve with changes directly proportional to the excitation reactance $\left(X_{\mathrm{ce}}\right)$ or inversely proportional to the excitation capacitance $\left(C_{\mathrm{e}}\right)$. The voltage generation process in SEIG can be completed from the intersection of the magnetizing curve with the excitation curve [15,22], as shown in Figure 5b. The point of intersection of these two curves can occur in the region of saturation, linear or initial region. The voltage generation process is claimed to be successful if the intersection of the two curves occurs in the saturation region. If the two curves intersect in a linear region, intersection will occur at many points, which triggers the voltage generation process to become unstable. Meanwhile, if the intersection occurs in the initial area, then the generator will only generate a very small voltage. 


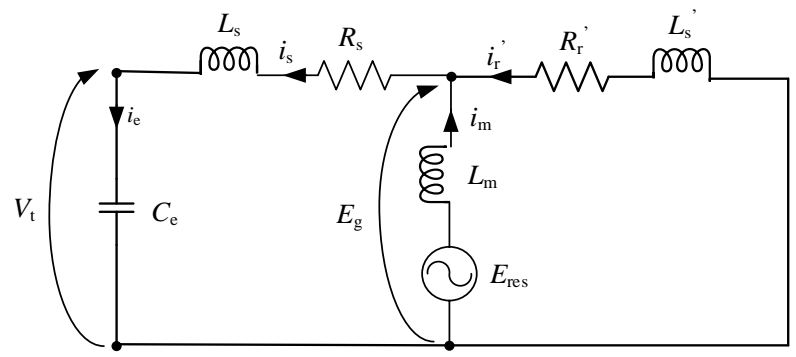

(a)

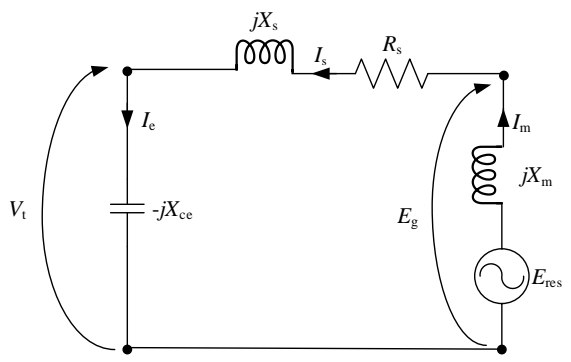

(b)

Figure 4. The SEIG equivalent circuit on the asynchronous operating mode (a) equivalent circuit on no load conditions, (b) simplified equivalent circuit

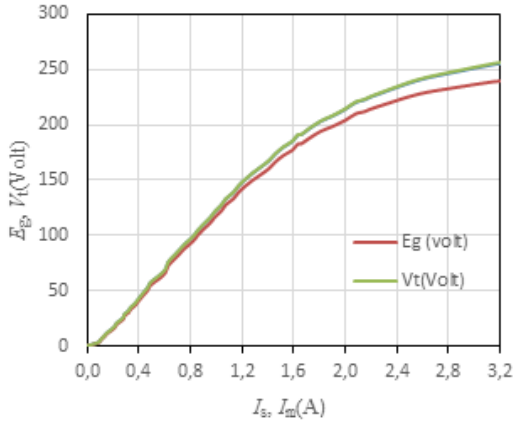

(a)

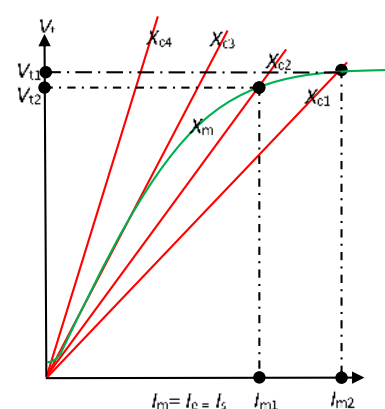

(b)

Figure 5. The relationship between the magnetization curve $\left(X_{\mathrm{m}}\right)$ and the excitation curve $\left(X_{\mathrm{ce}}\right)$ in the voltage generation process of SEIG. (a) magnetizing curve in terms $E_{\mathrm{g}}$ and $V_{\mathrm{t}}$ (b) intersection of the magnetization curve with several exc. Curves

\section{ANALYSIS AND EXPERIMENTAL SET-UP}

\subsection{Analysis}

As discussed in session 2.2, the process of voltage generation at the SEIG can be simply solved from the intersection between the magnetization curve $\left(X_{\mathrm{m}}\right)$ and the excitation curve $\left(X_{\mathrm{ce}}\right)$. The function of the magnetization curve can be defined by the following equation:

$$
X_{\mathrm{m}}: V_{\mathrm{t}}=g\left(I_{\mathrm{m}}\right) ; X_{\mathrm{ce}}: V_{\mathrm{ce}}=h\left(I_{\mathrm{m}}\right)
$$

If the magnetization curve equation is approximated by the polynomial interpolation method, then its function can be expressed by the following equation:

$$
g\left(I_{\mathrm{m}}\right)=a_{0}+a_{1} I_{\mathrm{m}}+a_{2} I_{\mathrm{m}}{ }^{2}+a_{3} I_{\mathrm{m}}{ }^{3}++a_{\mathrm{n}-1} I_{\mathrm{m}}{ }^{\mathrm{n}-1}+a^{\mathrm{n}} I_{\mathrm{m}}{ }^{\mathrm{n}}
$$

The constant values of $a_{1}, a_{2}, a_{3}$, $a_{\mathrm{n}-1}, a_{\mathrm{n}}$ can be solved using the polyfit function in MATLAB [23]. The excitation curve can be expressed by the following function:

$$
h\left(I_{\mathrm{m}}\right)=X_{\mathrm{ce}} I_{\mathrm{m}}
$$

The difference between the magnetization curve and the excitation curve can be solved by this following equation:

$$
f\left(I_{\mathrm{m}}\right)=g\left(I_{\mathrm{m}}\right)-h\left(I_{\mathrm{m}}\right)
$$

The intersection of these two curves can be solved by determining the root of the following equation: 


$$
f\left(I_{\mathrm{m}}\right)=a_{0}+\left(a_{1}-X_{\mathrm{ce}}\right) I_{\mathrm{m}}+a_{2} I_{\mathrm{m}}{ }^{2}+a_{3} I_{\mathrm{m}}{ }^{3}++a_{\mathrm{n}-1} I_{\mathrm{m}}{ }^{\mathrm{n}-1}+a_{\mathrm{n}} I_{\mathrm{m}}{ }^{\mathrm{n}}=0
$$

while,

$$
f^{\prime}\left(I_{\mathrm{m}}\right)=\left(a_{1}-X_{\mathrm{ce}}\right)+2 a_{2} I_{\mathrm{m}}+3 a_{3} I_{\mathrm{m}}^{2}+.+(\mathrm{n}-1) a_{\mathrm{n}-1} I_{\mathrm{m}}{ }^{\mathrm{n}-2}+\mathrm{n} a_{\mathrm{n}} I_{\mathrm{m}}{ }^{\mathrm{n}-1}
$$

To determine the root of equation (6), Newton Raphson's iteration method is used, with the equation for solving each iteration as follows [24,25]:

$$
I_{\mathrm{m}}^{\text {new }}=I_{\mathrm{m}}-\frac{f\left(I_{\mathrm{m}}\right)}{f^{\prime}\left(I_{\mathrm{m}}\right)}
$$

$I_{m}{ }^{\text {new }}=$ value of magnetization current at the $k$-iteration

$I_{\mathrm{m}} \quad=$ value of magnetization current at the $(k-1)$-iteration

Overall, the analysis of the effect of residual magnet availability on the generation of SEIG terminal voltages is completed through the steps arranged in the flowchart in Figure 6. As shown in Figure 6, the magnetization curve data in variations of $E_{\mathrm{g}}$ (i) and $I_{\mathrm{m}}$ (i) are obtained from saturation measurements (see Appendix). Whereas the magnetization curve data in the variation $V_{\mathrm{t}}$ (i) with $I_{\mathrm{m}}$ (i) is calculated through (1). The determination of the value of the excitation capacitor by operating the generator with the availability of sufficient residual magnetism and zero load conditions, so that the terminal voltage reaches a nominal value. The frequency value of the voltage generated by the generator is set at $50 \mathrm{~Hz}$. In this iteration, the initial condition $I_{0}$ can be set to zero. For each iteration step $k$, a new value of the $I_{\mathrm{m}}{ }^{\text {new }}$ magnetization current is calculated. The iteration process is stopped, if $\left|I_{\mathrm{m}}-I_{\mathrm{m}}{ }^{\text {new }}\right|$ reach smaller or equal to $\varepsilon$, where in the process of this diagram set $\varepsilon=10^{-5}$. The analysis process is carried out for a variety of residual magnetism conditions, ranging from the availability of strong residual magnetism to the availability of very low residual magnetism, so that no more voltage can be generated. In this study, there are 6 effects of the availability of residual magnet conditions analyzed on the generation voltage of SEIG. All results of the analysis will be discussed in session 4.
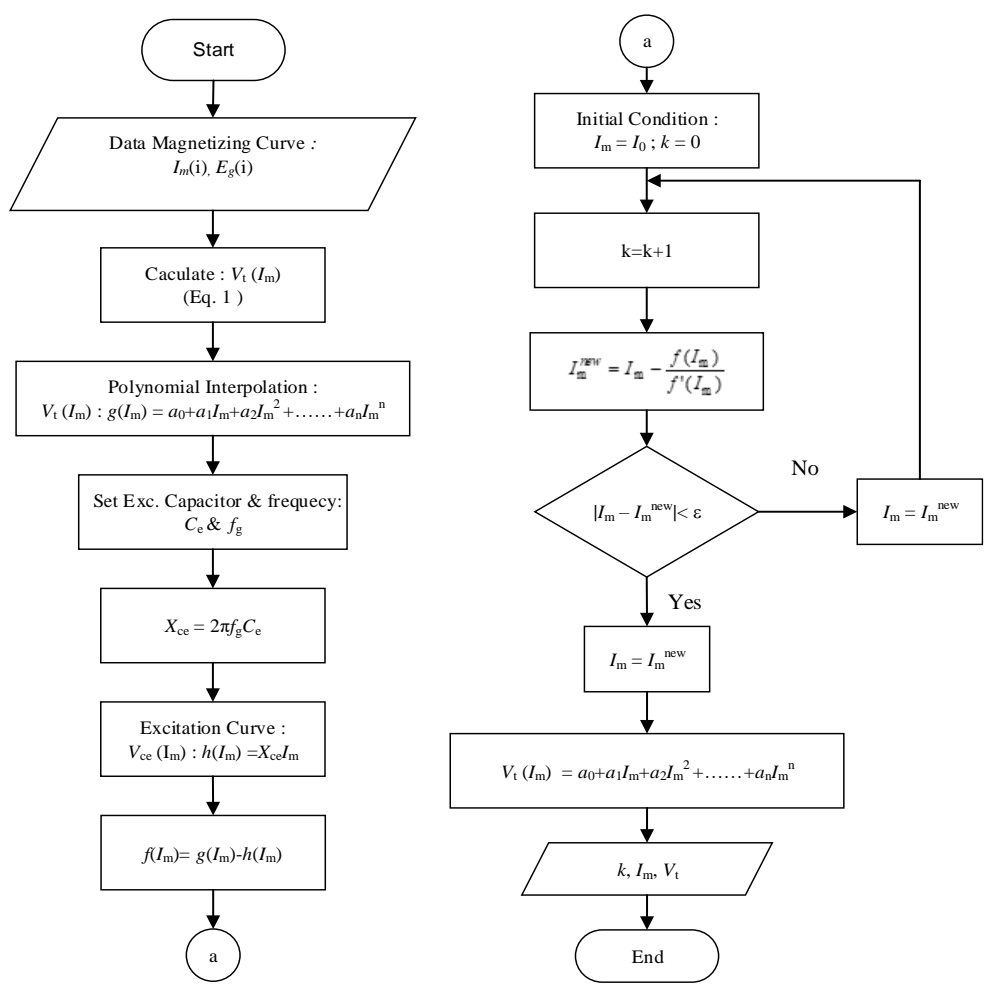

Figure 6. Flow chart for effect analysis of the residual magnetism availability to the voltage generation process 


\subsection{Experimental set-up}

In order to verify the results of the analysis, a series of experiment are conducted in the laboratory. This test applies the squirrel-cage induction machine of $1.5 \mathrm{~kW}, 380 \mathrm{~V}, 3$-phase, $50 \mathrm{~Hz}, 4$ poles, which is equipped with $12 \mathrm{mF}$ excitation capacitors that connected in delta. This machine parameters obtained from the test results are $R_{\mathrm{s}}=4,38 \Omega$ and $X_{\mathrm{s}}=3,61 \Omega$.

The laboratory testing process begins with the demagnetization process of the SEIG through loading the generator at its critical point, so that the generator voltage drops to zero suddenly. In this condition, the voltage caused by the residual magnetism is close to zero. The next process, the dc current is injected into one of the stator phase windings from the SEIG, so that $E_{\text {res }}$ can be obtained at the expected value. Then, the rotor of SEIG is rotated with the motor at $1506 \mathrm{rpm}$ and $E_{\text {res }}$ are measured. Next, the excitation capacitor is switched on the SEIG terminal under no-load condition, and the terminal voltage generated $\left(V_{\mathrm{t}}\right)$ and the magnetization current $\left(I_{\mathrm{m}}\right)$ is measured. The testing process is repeated, each for the availability of strong, weak, and critical residual magnetism.

\section{RESULTS AND DISCUSSION}

4.1. The analysis results of voltage generation processes under strong residual magnetism availability conditions

Figure 7 has shown the analysis results of the voltage generation process in the SEIG under conditions of availability of strong residual magnetism, namely Eres $=4.27$ Volts and Eres $=2.73$ Volts. As shown in figure 7 , the intersection of the curve only occurs in the saturation region area, namely: at $(\mathrm{Im}=$ 2,831 A, Vt $=220,07$ Volts $)$ for Eres $=4.27$ Volts and at $(\mathrm{Im}=2,799 \mathrm{~A}, \mathrm{Vt}=217,54$ Volts $)$ for Eres $=2.73$ Volts. Whereas in the initial region, the two curves do not intersect. This has shown that the voltage generation process at SEIG has been successful for both conditions of the availability of residual magnetism.
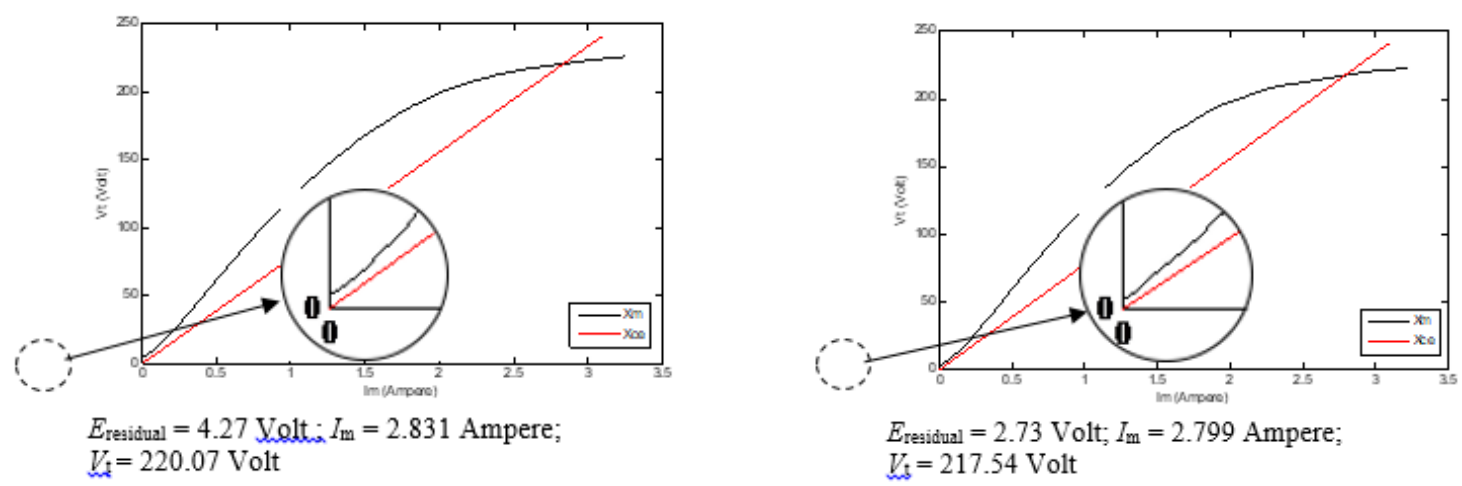

Figure 7. The analysis results of voltage generation process under strong residual magnetism availability conditions

\subsection{The results of the analysis of voltage generation processes under critical residual magnetism availability conditions}

The analysis results of the voltage generation process on the SEIG in conditions of critical residual magnetism availability, namely Eres $=1.04$ Volts and Eres $=0.993$ Volts, are shown in figure 8 . As shown in this figure, for Eres $=1.04$ Volts, the process of voltage generation is still successful because at the initial area does not occur at the intersection of the curve. However, when the residual voltage of residual magnetism decreases to Eres $=0.993$ Volts, the voltage generation process cannot have reached the expected value (nominal value). This happens because there are 2 intersection points of the curve, namely in the initial area $(\operatorname{Im} 1=0.109 \mathrm{~A}, \mathrm{Vt} 1=8.47$ Volts $)$ and the saturation area $(\operatorname{Im} 2=2.761 \mathrm{~A}, \mathrm{Vt} 2=214.58$ Volts $)$. 

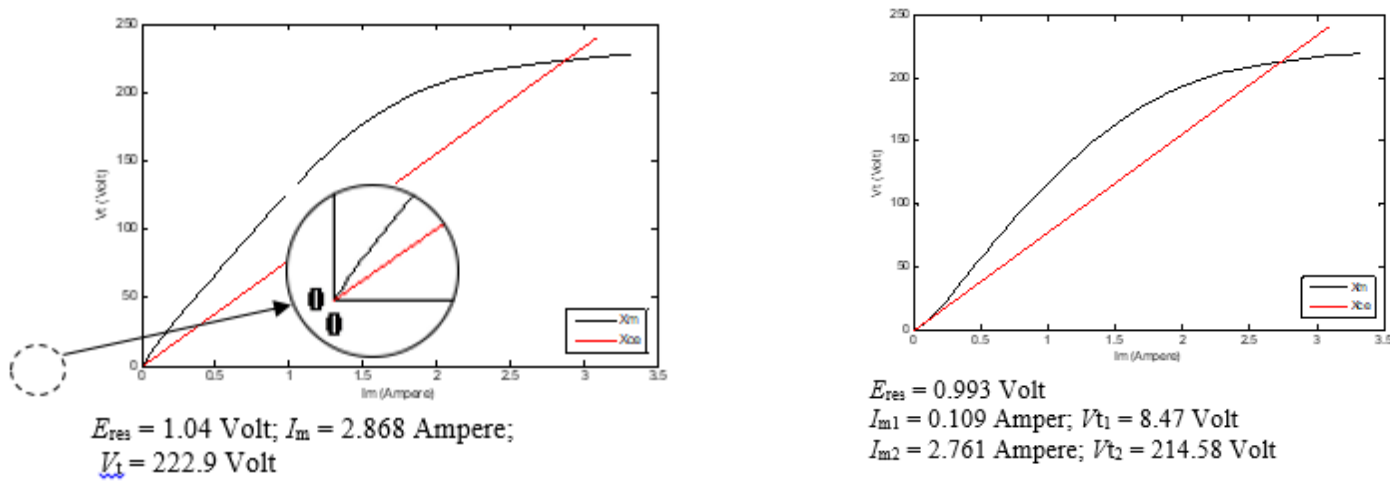

$E_{\text {res }}=0.993$ Volt

$I_{\mathrm{ml}}=0.109$ Amper; $V \mathrm{t}_{1}=8.47$ Volt

$I_{\mathrm{m} 2}=2.761$ Ampere; $V \mathrm{t}_{2}=214.58$ Volt

Figure 8 . The analysis results of voltage generation process under critical residual magnetism availability conditions

\subsection{The analysis results of voltage generation process under weakening residual magnetism availability conditions}

Figure 9 have shown the analysis results of the generation voltage process on the SEIG under weak residual magnetism availability conditions, namely $E_{\text {res }}=0.487$ Volts and $E_{\text {res }}=0.088$ Volts. As shown in figure 9, for both conditions, the intersection of the magnetization curve and the excitation curve occurs at two points. Therefore, in both of these conditions, the generator only generates a small voltage, namely $V_{\mathrm{t}}=$ 10.54 Volts in the residual magnetism state with $E_{\mathrm{res}}=0.487$ Volts and $V_{\mathrm{t}}=10.54$ Volts in the residual magnetism state with $E_{\text {res }}=0.088$ Volts. This means that the voltage generation process to reach nominal voltage was not successful for both conditions of the residual magnetism availability.
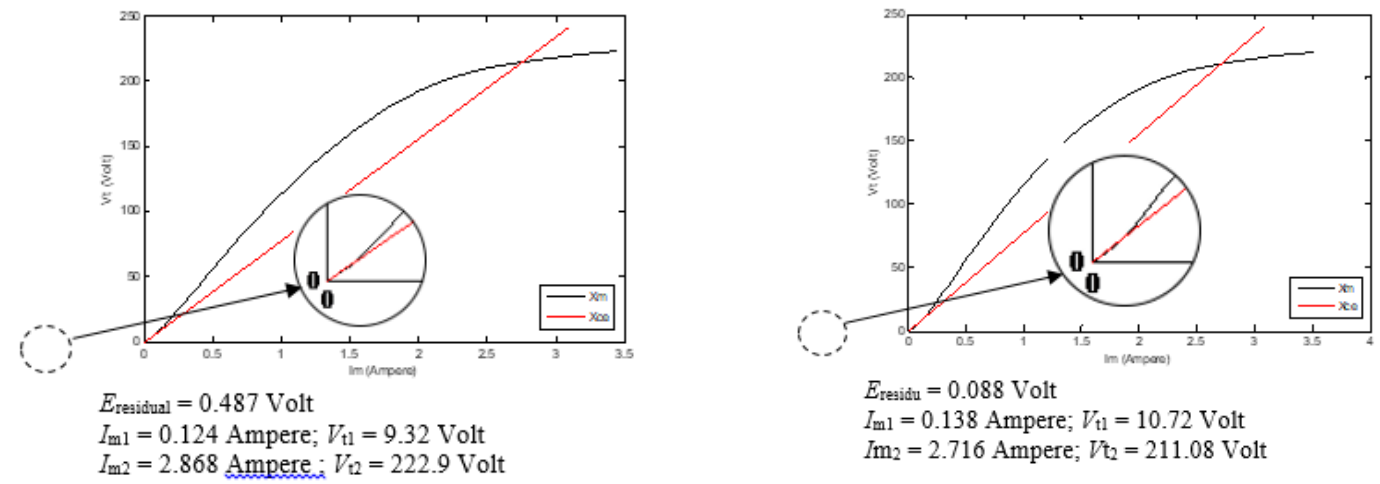

Figure 9. The analysis results of voltage generation process under weak residual magnetism availability conditions

\subsection{Comparison of analysis and testing results}

The experimental tests are conducted to check the validity of the results of the analysis discussed in sessions 4.1 to session 4.3. Figure 10 shows the comparison between the analysis results and the test results for various variations in the availability of residual magnetism to the voltage generated by SEIG. As shown in this figure, the simulation results and experiment results both show that the generator failed to generate a terminal voltage at its nominal value for an $E_{\text {res }}$ value below 1.04 Volt. At $E_{\text {res }}$ values above 1.04 volt, both curves have indicated the generator succeeded in generating its terminal voltage at nominal value. The simulation results and the test results show that the critical value of the remaining magnetic availability occurs at the value of $E_{\text {res }}=1.04$ Volt. From the description above, the analysis results are in line with the test results, so the validity of the model and the analysis method are sufficiently tested. 


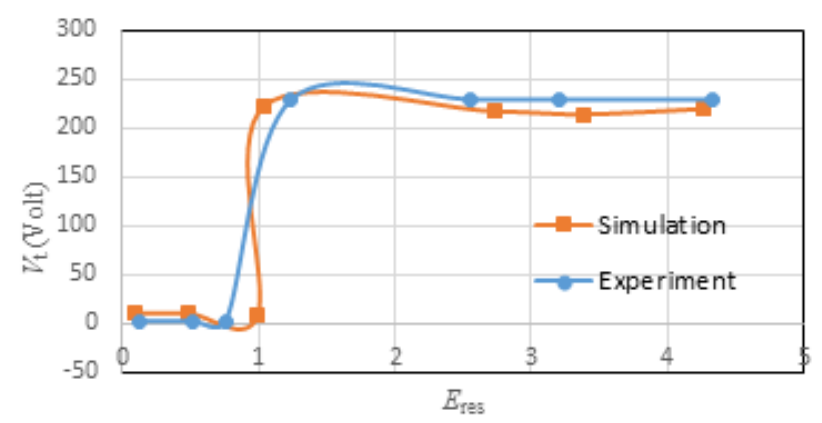

Figure 10. The comparison of simulation and test results

\section{CONCLUSION}

The effect of the availability of residual magnetism on the success of the terminal voltage generation process for SEIG on its nominal value has been successfully analyzed using Newton Raphson's iteration method. The availability of residual magnetism with residual voltage values below 1.04 Volt will cause the failure of the SEIG to generate the terminal voltage at its nominal value. Meanwhile, the availability of residual magnetism in SEIG with residual voltage values above 1.04 Volt, will succeed in generating terminal voltage at its nominal value. For SEIG used as the object of this study, the value of $E_{\text {res }}=1.04$ Volt is a critical value of the availability of residual magnets $\left(E_{\text {critical }}\right)$. The decrease in $E_{\text {res }}$ value of SEIG can be caused by various conditions, such as: short circuit fault, lack of reactive power, operation of the generator at the critical point etc. Therefore, for the voltage generation process in SEIG to be successful, it must be ensured that the residual voltage value must be above its critical value.

\section{ACKNOWLEDGEMENTS}

Author would like thanks to Andalas University for the financial support this work, through PDUPT Funding (No. T/5/UN.16.17/PT.01.03/PD-EET/2019).

\section{REFERENCES}

[1] Li Wang, Ping-Yi Lin, "Analysis of a Commercial Biogas Generation System Using a Gas Engine Induction Generator Set, IEEE Transactions on Energy Conversion, vol. 24, no. 1, pp. 230-239, 2009.

[2] E. Muljadi, C.P. Butterfield, H. Romanowitz, R. Yinger, "Self Excitation and Harmonics in Wind Power Generation", National Renewable Energy Laboratory, November 2004.

[3] R. C. Bansal, "Three-Phase Self-Excited Induction Generators: An Overview", IEEE Transactions on Energy Conversion, Vol. 20, No. 2, June 2005.

[4] M. Benmeziane, S. Zebirate, A. Chaker1, and Z. Boudjema, "Fuzzy sliding mode control of doubly-fed induction generator driven by wind turbine", International Journal of Power Electronics and Drive System (IJPEDS), Vol. 10, No. 3, pp. 1592-1602, 2019.

[5] Refdinal Nazir, Krismadinata, and Rizka Amalia, "The Camparison Of Harmonic Distortion Self-Excited Induction Generator with Isolated Synchronous Generator Under Non-Linear Loads", International Journal of Power Electronics and Drive System (IJPEDS), vol. 6, no. 4, pp. 759-771, 2015.

[6] Refdinal Nazir, Syafii, Andi Pawawoi, Fajril Akbar and Axel Dorinza, "Differences in the impact of harmonic distortion due to the installation of electronic load controller in self-excited induction generator and synchronous generator", International Journal of Power Electronics and Drive System (IJPEDS), vol. 10, no. 1, pp. 104-116, 2019.

[7] Refdinal Nazir, "Analysis of Harmonic Currents Propagation on the Self-Excited Induction Generator with Nonlinear Loads”, J Electr Eng Technology, Vol. 9, No. 6, pp. 1935-1943, 2014.

[8] Refdinal Nazir, Andi Pawawoi, Riska Amalia, "Harmonic Effects Analysis of Electronic Loads Controller on Self Excited Induction Generator (SEIG) Operations", Indonesian Journal of Electrical Engineering and Computer Science, vol. 8, no. 2, pp. 273-280, 2017.

[9] Rajasekhara R. C., et al., "Performance of a Self-Excited Induction Generator with DSTATCOM-DTC DriveBased Voltage and Frequency Controller", IEEE Transactions on Energy Conversion, vol. 29, no. 3, 2014.

[10] Jinn-Chang Wu, "Novel Circuit Configuration for Compensating for the Reactive Power of Induction Generator", IEEE Transctions on Energy Conversion, vol. 23, no. 1, March 2008.

[11] Hayder Hussein Kadhum, et al., "The influence of iron losses on selecting the minimum excitation capacitance for self-excited induction generator (SEIG) with wind turbine", Indonesian Journal of Electrical Engineering and Computer Science, Vol. 19, No. 1, pp. 11-22, 2020. 
[12] Lokesh Varshney, R.K. Saket, "Reliability evaluation of SEIG rotor core magnetization with minimum capacitive excitation for unregulated renewable energy applications in remote areas", Ain Shams Engineering Journal, vol. 5, pp. 751-757, 2014.

[13] Rishikesh Choudhary and R.K. Saket, "A critical review on the self-excitation process and steady state analysis of an SEIG driven by wind turbine", Renewable and Sustainable Energy Reviews, vol. 47, pp. 344-353, 2015.

[14] D.B. Watson, et al., "Controllable d.c. power supply from wind-driven self-excited induction machines", Proc. IEE, Vol. 126, No. 12, December 1979.

[15] Elder, J.M.; Boys, J.T. \& Woodward, J.L. "Self-Excited Induction in induction generators.”, IEE Proceedings. Vol. 130, Pt. B., No. 2, pp.103-108, 1984.

[16] Refdinal Nazir, "Development of Self-Excited Induction Generator for Variable Speed and Load Conditions", Ph.D. Dissertation. Universiti Teknologi Malaysia, 1999.

[17] Wejdan S. A., and Annette M., "Self-Excitation and Stability at Speed Transients of Self-Excited Single-Phase Reluctance Generators", IEEE Transctions on Sustainable Energy, vol. 4, no. 1, January 2013.

[18] Will Knapek, "Residual Magnetism", Omicron, 2012.

[19] Maurer Magnetic AG, "Measuring Residual Magnetism of Ferromagnetic Parts", (c) Maurer Magnetic AG 04.2014.

[20] Maurer Magnetic AG, "Demagnetization of large surface objects", (c) Maurer Magnetic AG 04.2015.

[21] Oriano Bottauscio, et al. "Role of Magnetic Materials in a Novel Electrical Motogenerator for the More Electric Aircraft", IEEE Transctions on Magnetics, vol. 50, no. 4, April 2014.

[22] Juliano B. Padilha, et al., "Vector Hysteresis Model Associated with FEM in a Self-Excited Induction Generator Modeling", IEEE Transctions on Magnetics, vol. 52, no. 3, March 2016.

[23] Math Works, SIMULINK-MATLAB Library, 2012.

[24] Steven Chapra and Raymond P. Canale, "Numerical Methods for Engineers", Mc. Graw-Hill, 2015.

[25] Stanisław Rosłoniec, "Fundamental Numerical Methods for Electrical Engineering", Springer-Verlag, Berlin Heidelberg, 2008. 